\title{
A avaliação no contexto da formação médica brasileira
}

\author{
Student evaluation in the context of medical \\ training in Brazil
}

\author{
Maria das Graças Mota MourãoI \\ Antônio Prates Caldeira ${ }^{\mathrm{I}}$ \\ José J. B.Vasconcelos Raposo
}

\section{PALAVRAS-CHAVE \\ - Educação médica \\ - Avaliação \\ - Ensino superior}

Recebido em: 16/07/2008 Reencaminhado em: 15/10/2008 Aprovado em: $17 / 11 / 2008$
REVISTA BRASILEIRA DE EDUCAÇ̃̃O MÉDICA

\footnotetext{
${ }^{I}$ Universidade Estadual de Montes Claros, Montes Claros, Minas Gerais, Brasil.

Iniversidade Estadual de Montes Claros, Montes Claros, Minas Ger
II Universidade de Trás-os-Montes e Alto Douro, Vila Real, Portugal.
}

\section{A B S T R A C T}

This article aims to contribute to the discussion on student evaluation in higher education in the current context of Brazilian medical schools, with a view toward stimulating reflection and discussion by those involved in the educational process. In our view, research on the theme allows us to rethink practices and develop more participatory and process-oriented proposals, considering the institution's own experience, diversity, and complexity. We thus discuss the self-evaluation approach in an ethical and responsible light, for the medical school to achieve a critical and participatory reflection on its actions and identify the actual role in its involvement with the community and the contribution to its development. The aim is to describe student evaluation as a force for change, considering the relationship between qualitative and quantitative aspects, the nature of the pedagogical relationship, and the objectives, in light of the complexity and dynamism in the teaching process. 


\section{INTRODUÇÃO}

A temática da avaliação institucional torna-se cada vez mais presente nos debates educacionais e já é uma realidade no plano da política educacional e da legislação, inclusive com instrumentos oficiais. A intensificação desse debate se deve ao contexto político internacional, que sofreu inúmeras modificações desde o final da década de 1970, com destaque para fatores como: o esgotamento do modelo fordista de desenvolvimento do capitalismo; a revolução técnico-científica, que propiciou uma mudança no processo produtivo, com a introdução da informática e da microeletrônica; a crise de financiamento do Estado de bem-estar social nos países da Europa Ocidental e Estados Unidos.

Tais fatos abriram espaço para a implantação das políticas neoliberais, com os governos da Inglaterra e dos Estados Unidos. Durante a década de 1980, esses governos iniciaram privatizações, diminuíram o papel do Estado na economia, reduziram os direitos sociais e propagaram internacionalmente essas novas diretrizes político-econômicas. No caso da América Latina, a partir da década de 1970, o governo do Chile, sob a influência dos organismos internacionais, já aplicava a política neoliberal. A orientação doutrinária neoliberal coloca a redução dos gastos públicos e a produtividade como foco principal das políticas públicas, surgindo daí a ênfase na avaliação como função central do poder público e como instrumento indispensável de governo.

Inserida neste contexto, a educação superior tem despertado o interesse da sociedade de forma significativa desde a década de 1980, quando os países industrializados e os latino-americanos empreenderam importantes reformas em seus sistemas de educação superior. Com a globalização do mercado educacional nos últimos anos, tais reformas nesse nível de ensino se dinamizaram, diversificando os provedores, os tipos de instituições, os perfis dos docentes, disponibilizando novas ofertas educativas, ampliando as matrículas e apresentando um aumento crescente das demandas e da competitividade. Em resposta aos novos desafios gerados pela globalização econômica, a educação superior é chamada a conciliar as exigências de qualidade e inovação com as necessidades de ampliar o acesso e diminuir as assimetrias sociais ${ }^{1}$.

Nesse cenário de aceleradas mudanças econômicas e sociais e de reforma das instituições educacionais, principalmente aquelas que se dedicam à formação dos indivíduos e à produção de conhecimentos e técnicas, considerados importantes capitais econômicos, os processos de avaliação e de regulação da educação superior ganham centralidade nos países que buscam se modernizar. Esses processos são sustentados por argumentos diversos, que vão desde a necessidade de os Estados assegurarem a qualidade e os controles regulatórios, a distribuição e o uso adequado dos recursos públicos, a expansão segundo critérios estabelecidos por políticas institucionais e do sistema, até a necessidade de dar fé pública, de orientar o mercado consumidor dos serviços educacionais e de produzir informações úteis para as tomadas de decisão ${ }^{1}$.

Assim, as condições de produção e os resultados obtidos pelas instituições assumem grande importância, sendo exigidos, aperfeiçoados e detalhados constantemente. Percebe-se o fortalecimento das avaliações somativas, dos mecanismos de controle, regulação e fiscalização e a prestação de contas, diferentemente das avaliações formativas, participativas, voltadas aos processos, às diversidades identitárias e à complexidade das instituições.

No Brasil, assim como na maioria dos países do mundo ocidental, a experiência em avaliação foi influenciada pela literatura norte-americana. Nos Estados Unidos, a origem das avaliações em grande escala, no âmbito do Estado, ocorreu após a Segunda Guerra Mundial. As avaliações foram concomitantes ao processo de construção do Estado de Bem-Estar. Farias², em palestra proferida na Comissão Central de Graduação/Unicamp, tece algumas explicações sobre o Estado de Bem-Estar:

O Estado coloca as grandes políticas públicas, os grandes conceitos. A partir daí ele desenvolve sistemas de avaliação. Tais sistemas de avaliação alimentam as bases de dados dos órgãos elaboradores de políticas e estes tomam decisões, na outra ponta, que afetam o financiamento recebido pelas instituições. Fixam políticas, definem processos de avaliação e discutem acesso a recursos em função dos resultados do processo avaliativo.

Assim, o Estado Avaliador usa o tripé política, avaliação e distribuição de recursos como uma poderosa máquina de implementação de políticas públicas, ancorada na questão da avaliação. De acordo com Farias ${ }^{2}$, um movimento no sentido de abandonar o controle burocrático que utilizava e avançar para um controle baseado nos processos de avaliação.

Neste artigo, pretendemos aprofundar a discussão acerca da avaliação no ensino superior, no contexto atual das escolas médicas brasileiras, a fim de estimular a reflexão e a discussão de todos aqueles que de uma forma ou de outra estejam envolvidos no processo educativo. Entendemos que pesquisas a respeito da temática nos permitem repensar práticas e construir propostas mais participativas, voltadas aos processos, considerando a própria experiência, a diversidade e a complexidade da instituição de formação médica. 
Num primeiro momento, abordaremos a avaliação do ensino superior no contexto brasileiro e sua trajetória no ensino superior. Na sequência, situaremos a avaliação na escola médica, no contexto atual, articulada ao Sistema de Avaliação Nacional (Sinaes), e a complexidade da formação médica a partir de estudos e experiências inovadoras em instituições que adotaram o currículo integrado e as metodologias ativas como proposta de formação médica.

\section{A AVALIAÇÃO NO CONTEXTO BRASILEIRO}

No Brasil, a avaliação no âmbito do Estado tornou-se obrigatória somente para o sistema educacional, tendo sido institucionalizada na década de 1990, anos marcados pelo crescimento político das orientações neoliberais de Estado. Mas, historicamente, registram-se no Brasil algumas experiências de avaliações a partir do final dos anos 1970. Inicia-se com a avaliação da pós-graduação pela Capes, especialmente voltada aos cursos de mestrado e doutorado. Nos cursos de graduação, as primeiras ideias sobre o tema avaliação surgem em 1983 com a instituição, pelo Ministério da Educação, do Programa de Avaliação da Reforma Universitária (Paru), que enfatizava a gestão das Instituições de Ensino Superior (IES), a produção e a disseminação de conhecimentos. O Paru sofreu a influência do setor de pós-graduação, que, no início da década de 1980, contava com um sistema de avaliação de amplo reconhecimento por sua qualidade. Para Dias et al. ${ }^{3}$, a graduação não dispunha de uma proposta comparável à do sistema de avaliação da pós-graduação e, portanto:

[...] necessitava de um mecanismo que pudesse apontar em que medida a Reforma Universitária realmente se efetivou, quais as vantagens alcançadas e os problemas enfrentados pelos diversos tipos de cursos e instituições. (Dias 2001 apud Dias et $\mathrm{al}^{3}$ 2006, p.438)

Gonçalves Filho (2004) apud Dias et al ${ }^{3}$ (2006, p.438) argumenta "que os enfoques avaliativos surgidos nos Estados Unidos com base no funcionalismo neoliberal influenciaram o Brasil na concepção do Paru." Salienta que "as premissas de tais enfoques estavam associadas às crenças advindas das novas concepções de democracia." Todavia, o programa foi substituído por iniciativas governamentais, como a constituição da "Comissão de Notáveis", em 1985, e do Grupo Executivo da Reforma da Educação Superior (Geres), em 1986.

Farias $(2001)^{2}$ explica que o Estado Avaliador usa o tripé política, avaliação e distribuição de recursos como: um mecanismo para passar os seus projetos políticos, por um lado, e, por outro, para exercer o controle da adequação das instituições aos projetos políticos. [...] Esse é um fenômeno que não é novo. Ele tem início nos governos de Reagan - Estados Unidos - e Thatcher - Inglaterra - como estratégia intencional destes governos e durante décadas foram exercitados nas políticas públicas desses países. Ao final da década de oitenta, começaram a ser introduzidos em organismos internacionais (FMI, BID, etc.) e suas repercussões começam a ser sentidas nas instituições no Brasil.

No final da década de 1980 e início dos anos 1990, algumas universidades iniciaram experiências de autoavaliação que contribuíram para criar um espaço de interlocução entre o Ministério da Educação e as instituições federais, representadas pela Associação das Instituições Federais do Ensino Superior (Andifes). Essas experiências subsidiaram a construção do Programa de Avaliação Institucional das Universidades Brasileiras (Paiub), que contou com o apoio da Secretaria de Educação Superior.

O Paiub foi a primeira tentativa de implantação de um sistema nacional de avaliação institucional da educação superior no Brasil. Este programa, oficialmente criado em 1993, surge de um movimento interno às universidades, liderado por atores sociais que vivenciavam a educação superior, com embasamento teórico e metodológico adequado ao momento. O objetivo era propor um modelo de programa de avaliação no contexto nacional, resguardando as especificidades institucionais. Caracterizou-se como um programa construído pelas universidades públicas, como uma resposta ao desafio de implantar um sistema de avaliação institucional centrado na graduação e que tivesse por objetivo desenvolver um processo de avaliação institucional que valorizasse as especificidades de cada instituição.

Assim, o programa de avaliação deveria atender a três exigências básicas: ter um processo contínuo de aperfeiçoamento do desempenho acadêmico, atuar como uma ferramenta para o planejamento da gestão universitária e atender a um processo sistemático de prestação de contas à sociedade. Ou seja, o Paiub fundamentava-se na ideia de que a universidade deveria ter um projeto voltado para a promoção da qualidade e suas ações baseadas na ética e no compromisso social. Para Rothen e Schulz ${ }^{4}$, o programa partia do pressuposto de que a avaliação das IES decorria dessas exigências da universidade contemporânea.

A proposta do Paiub sustentava-se em alguns princípios fundamentais, entre os quais o da adesão voluntária das universidades, e previa a autoavaliação como etapa inicial do processo, que 
em seguida se estenderia a todas as dimensões da instituição, completando-se com a avaliação externa. É importante salientar a contribuição do Paiub na consolidação de uma cultura institucional de avaliação, mesmo tendo vida (oficial) curta. O programa promoveu mudanças institucionais, transformando-se num modelo de avaliação institucional (interno). Seus princípios básicos são ainda hoje adotados em muitas delas. Deve-se também reconhecer o papel das universidades presentes nas discussões que levaram à criação de mecanismos que propiciassem a reflexão crítica da educação superior no Brasil.

Em 1996, é introduzido, por Lei, o Exame Nacional de Cursos (ENC), mais conhecido como "Provão", em âmbito nacional, juntamente com outros mecanismos avaliativos, como a Avaliação das Condições de Ensino (ACE) e a avaliação para credenciamento de IES privadas, com o propósito de nivelar as instituições em termos de qualidade. O ENC apresenta concepções distintas de avaliação do Paiub, pois sua ênfase recai sobre os resultados e não sobre o processo; seu foco é o ensino, o curso, estabelecendo-se ranqueamentos das IES.

O ENC mostrou-se insuficiente e fragmentado para responder ao questionamento referente ao tipo de educação superior oferecido pelas instituições brasileiras. Costa ${ }^{5}$, em entrevista ao jornal Beira do Rio, diz:

Considero que o ENC não deu certo, basicamente por dois aspectos: a) não atendeu às finalidades a que se propusera, que era o da melhoria da qualidade de ensino e apoiar o CNE em suas deliberações sobre a regulação do ensino de graduação, apesar de certos registros de melhorias em alguns cursos, na perspectiva de seus gestores; b) o Provão serviu para iludir a sociedade sobre a qualidade dos cursos e IES, já que o indicador dessa qualidade é a notação alfabética, cujos resultados não retratam efetivamente conceitos. Assim, um A não significa que o curso seja excelente, nem um E que o curso seja, efetivamente, péssimo. Portanto, desorienta a população sobre a qualidade dos cursos, nem serve como subsídio à regulação e é impotente para elaborar políticas públicas de educação.

Segundo a entrevistada ${ }^{5}$,

[...] o Provão, ao tomar o aluno como sujeito da avaliação, não poderia assumir esse instrumento como representativo da avaliação da instituição, ou da educação superior. Distante de atin- gir a sua meta (avaliação de cursos), [...] longe também de expressar as reais condições de funcionamento de todas as áreas de conhecimento científico onde os cursos de graduação se inserem além do que os altos custos de sua operacionalização colaboram para retratar a ineficácia desse instrumento de avaliação.

O fracasso do ENC desencadeou um processo de discussão que deu origem ao Sistema Nacional de Avaliação da Educação Superior (Sinaes). O novo sistema visa integrar e garantir informações e análises da totalidade da educação superior, permitindo a instalação de políticas educativas, tanto em nível nacional, articuladas pelos órgãos pertinentes, quanto em âmbito institucional, articuladas pelas IES.

O Sinaes se alicerça na concepção de avaliação da educação superior sustentada na lógica de um conjunto de políticas públicas direcionadas para a expansão do sistema,

pela democratização do acesso de forma que a qualificação do mesmo se integre a um processo mais amplo de revalorização da educação superior. Contextualiza a educação superior ao mundo atual em que entre as finalidades da construção do saber se insere a intervenção social no sentido de reduzir as assimetrias sociais, propiciando condições para a construção de novas pontes de inclusão social. Portanto, o Sinaes amplia suas dimensões, objetos, procedimentos, integrando os vários instrumentos de avaliação (alguns deles já existentes mais adequados à nova lógica) e propondo outros, como o Paideia. Como tal, incorpora aos processos avaliativos todos os atores sociais, as dimensões sociais e todas as instâncias da educação superior. Busca assegurar as dimensões externas e internas, particular e global, somativo e formativo e os diversos objetos e objetivos da avaliação. ${ }^{1}$ (p. 83-4)

Na visão de Ristoff e Giolo (2006) ${ }^{6}$, a construção do Sinaes significou

retomar as experiências, objetivos e metas mais relevantes da avaliação da educação superior brasileira. Deve-se a isso o fato de o Sinaes ter sido transformado em política de Estado por meio da Lei 10.861, de 14 de abril de 2004. A Proposta assinala a centralidade da experiência do 
Paiub enquanto referência prática para o Sinaes. [...] incorporou grande parte dos princípios e diretrizes do Paiub, entre eles: o compromisso formativo da avaliação, a globalidade, a integração orgânica da autoavaliação com a avaliação externa, a continuidade, a participação ativa da comunidade acadêmica, o respeito à identidade institucional e o reconhecimento da diversidade do sistema. (p. 197)

Para os autores ${ }^{6}$, o Sinaes constitui um sistema, na medida em que:

- integra os instrumentos de avaliação;

- integra os instrumentos de avaliação aos de informação;

- integra os espaços de avaliação no Ministério de Educação;

- integra a autoavaliação à avaliação externa;

- articula, sem confundir, avaliação e regulação;

- propicia coerência entre avaliação e os objetivos e a política para a educação superior (p. 198).

A construção do Sinaes parte do pressuposto de que todas as avaliações da educação superior, realizadas no âmbito do Ministério da Educação, se organizem e se operacionalizem a partir de uma concepção que integre as metodologias, os momentos, os espaços e os instrumentos de avaliação e de informação. Essa iniciativa talvez constitua um dos mais importantes diferenciais entre o que foi construído com o Sinaes e as práticas antes existentes $^{6}$ (p.198).

Nesse sentido, Dias Sobrinho 7 explica que a avaliação exerceu papel central nas reformas da educação superior no Brasil, com procedimentos estanques de avaliação. Por isso, o sistema e os subsistemas educativos foram recortados por avaliações fragmentadas que atendiam a objetivos específicos, mas são incapazes de fornecer uma visão de globalidade.

Para obter essa visão globalizada, cabe às instituições buscar a avaliação educativa capaz de contribuir com a formação integral do estudante, nos aspectos tanto profissional quanto pessoal. Em outras palavras ${ }^{7}$,

a avaliação educativa, ao contrário, sem deixar de ser objetiva e controlar os processos científicos, pedagógicos e administrativos, tende a produzir os debates, a reconhecer a diversidade de ideias, a interpretar a pluralidade, a construir novos sentidos, a questionar a razão dos projetos e currículos, a valorar a inserção crítica e produtiva na sociedade, a dinamizar a construção da autonomia. (p. 189)
O Sinaes deve articular duas importantes dimensões: a) avaliação educativa propriamente dita, de natureza formativa, mais voltada à atribuição de juízos de valor e mérito com vistas a aumentar a qualidade e as capacidades de emancipação; e b) regulação, em suas funções de supervisão, fiscalização, decisões concretas de autorização, credenciamento, recredenciamento, descredenciamento, transformação institucional, etc., funções próprias do Estado $^{1}$ (p. 85).

O sistema para alcançar as instituições de ensino superior, em sua totalidade, possui três componentes principais: a avaliação das instituições, dos cursos e do desempenho dos estudantes. Esse modelo de avaliação tem como base a avaliação institucional, que compreende a avaliação externa e a interna, principalmente com seu componente central, a autoavaliação ${ }^{3}$.

Na perspectiva de seus criadores, o Sinaes deve se constituir efetivamente numa ampliação dos âmbitos, objetos, procedimentos e instrumentos de avaliação para além dos atualmente praticados, procurando sempre assegurar a integração, a participação, a globalidade, a relevância científica e social, a articulação da regulação com a emancipação, do institucional com o sistêmi$\operatorname{co}^{1}$ (p. 93-4).

O sistema de avaliação tem como princípios que respaldam sua fundamentação conceitual, política e justificativa operacional: Globalidade; Caráter Público; Respeito à Identidade e à Diversidade de Instituições e Cursos; Participação; Regulação e Supervisão. No princípio da Globalidade, a avaliação contempla a análise integrada das estruturas, das relações, do compromisso social, das atividades, das finalidades e da responsabilidade social das IES e de seus cursos. OCaráter Público da avaliação refere-se à disseminação pública dos procedimentos, dados e resultados dos processos avaliativos. Quanto ao Respeito à Identidade e à Diversidade de Instituições e Cursos, as IES têm a liberdade de desenvolver processos avaliativos que correspondam às suas necessidades e aos seus objetivos específicos. Para isso, devem estimular a participação dos docentes, discentes e pessoal técnico-administrativo das IES, bem como da sociedade. Já a Regulação e a Supervisão vinculam os processos de (re)credenciamento de IES, de autorização, de reconhecimento e renovação de reconhecimento de cursos de graduação à avaliação.

Para cumprir o proposto, o sistema conta com processos e bases de informação, entre eles o Processo de Avaliação Integrada do Desenvolvimento Educacional e da Inovação da Área (Paideia), que prioriza o enfoque de movimento e de integração, buscando compreender não só o "estado da arte" em determinado momento, mas, em especial, as dinâmicas e valores agregados em cada área do conhecimento ${ }^{1}$ (p.112). 
Assim, o Paideia pretende contribuir para a compreensão e a melhoria de realidades mais amplas, e não apenas realizar a simples verificação de rendimentos. $\mathrm{O}$ documento aponta três aspectos que precisam ser assegurados no processo: a) que esteja voltado à efetividade científica e social, e não basicamente à pretensão de medir e classificar; b) que seja capaz de compreender os dinamismos e as tendências da área; c) que esteja integrado a um real sistema de avaliação, isto é, que se articule coerentemente com outros instrumentos avaliativos ${ }^{1}$ (p.113).

Em síntese, são cinco as características básicas do Paideia:

1. é um processo de avaliação da trajetória da área ao longo do tempo;

2. avalia os conhecimentos dos alunos no meio e no final do curso;

3. é realizado por amostragem;

4. cada área é avaliada de dois em dois anos;

5. gera informações qualificadas que vão além dos conteúdos específicos da área profissionalizante.

OSinaes prevê a coordenação e a supervisão do processo por uma Comissão Nacional de Avaliação da Educação Superior, a Conaes, que deve propor e avaliar instrumentos, procedimentos e mecanismos de avaliação, organizar comissões de avaliação, analisar relatórios e elaborar pareceres e recomendações. Essa Comissão é composta por representantes do Inep, da Capes, do MEC, do corpo docente e discente das IES, e por membros de notório saber e competência em avaliação e gestão da educação superior. Às IES compete a constituição de Comissão Própria de Avaliação (CPA), encarregada da autoavaliação institucional e de relatar os resultados ao Inep.

A autoavaliação institucional, nesta abordagem, deve ter um caráter educativo, de melhora e de autorregulação. Deve buscar compreender a cultura e a vida de cada instituição em suas múltiplas manifestações. As comparações devem ser internas, devendo-se evitar rankings e classificações. Todos os dados devem ser consolidados em relatórios, essenciais e pertinentes, os quais, uma vez discutidos e aprovados pela comunidade, tornam-se documentos oficiais e públicos. Esses relatórios devem favorecer o desenvolvimento da avaliação institucional interna ${ }^{8}$ (p. 77).

De acordo com o documento, a participação efetiva dos atores universitários tornará mais significativo o processo de autoavaliação em termos educativos. Dessa forma, a autoavaliação é um processo social e coletivo de reflexão, produção de conhecimentos sobre a instituição e os cursos, por promover a compreensão de conjunto, a interpretação e o trabalho de transformação. O relatório de autoavaliação deve ser encaminhado à
Conaes, que, por sua vez, o encaminhará à(s) Comissão(ões) externa(s) de avaliação.

Para operacionalizar a avaliação institucional, especialmente em sua dimensão interna, cada IES, de acordo com suas características estruturais, deve

constituir uma ou mais comissões para organizar os processos avaliativos, coordenar os debates, acompanhar sua execução, assegurar a unidade entre os diversos setores, garantir rigor, efetuar a edição final dos documentos, auxiliar na identificação dos problemas, das potencialidades e das ações que devem ser empreendidas, promover estratégias de sensibilização e de informação permanente, buscando sempre a criação e a consolidação de uma cultura de avaliação permanente, rigorosa e efetiva para o desenvolvimento institucional ${ }^{8}$. (p. 77)

Nesse sentido, Rothen e Schulz ${ }^{4}$ analisam as diferenças conceituais e operacionais entre a proposta e a legislação, destacando como diferença fundamental da proposta da Comissão Externa de Avaliação (CEA) e da legislação que instaurou o Sinaes o entendimento da função da avaliação. Na proposta, defende-se, explicitamente, que a função predominante é a formação das IES; já na legislação, os resultados da avaliação serão referenciais básicos dos processos de regulação e supervisão da educação superior, uma vez que sugere que o controle deve ser articulado à avaliação educativa, isto é, que seja uma prática formativa e construtiva (CEA apud Rothen e Schulz ${ }^{4}$, p. 171).

Frente às experiências anteriores, o novo sistema de avaliação da educação superior enfrenta o desafio de ser eficiente e rigoroso, levando em conta as necessidades e possibilidades das diferentes regiões do Brasil, as áreas do conhecimento e a formação da força de trabalho nas diversas profissões. Em suma, o Sinaes propõe uma avaliação institucional integrada, que utiliza diversos instrumentos de avaliação. Isso permitirá às instituições fazerem eventuais correções de rota sob a supervisão de uma comissão nacional, envolvendo todos os atores e abrangendo os múltiplos aspectos da educação superior, avaliando as instituições de forma muito mais ampla e consistente.

\section{AVALIAÇÃO NA ESCOLA MÉDICA}

A avaliação da educação superior é um processo em constante mudança e tem sido cada vez mais valorizada em busca da qualidade da formação profissional. Inserida neste contexto, a 
medicina tem usado processos avaliativos para debater e acompanhar as transformações da área.

Pérez Sánchez e Alfonso ${ }^{9}$ argumentam que a educação médica é um processo de formação complexa, em que a qualidade é definida a partir de critérios de seu contexto social, sendo a avaliação um componente fundamental nessa busca de um ensino de qualidade:

La educación médica es un proceso de formación cultural, moral y ética que se interrelaciona e imbrica con la ideología, la ciencia, el arte y las tecnologías médicas de la sociedad en que se desarrolla. Y es de ahí que, el criterio de calidad educacional se define en este contexto, en términos de pertinencia social, calidad curricular y buen desempeno profesional, en estrecha relación con el sistema de valores imperantes.

Sendo assim, é fundamental que as escolas médicas avancem na experiência avaliativa das próprias instituições, utilizando todos os mecanismos possíveis de autoavaliação e de reflexão sobre sua missão, currículos, estratégias de ensino-aprendizagem e avaliação docente e discente. Nessa ótica, acercar-se desta temática significa articular elementos técnicos, bem como questões éticas e políticas na avaliação do curso. Independentemente de avaliar um programa, um curso ou o desempenho do aluno, questões como validade das medidas, confiabilidade entre avaliadores, premissas, variáveis, indicadores e instrumentos são chamadas a desvelar uma coerência que é complexa. Ainda, de acordo com Pérez Sánchez e Alfonso?:

Una actividad social que no puede ser simplificada a un enfoque tecnicista y conductual es la evaluación curricular, pues su base determinante es socioeconómica y su análisis no puede reducirse a una simple suma de un conjunto de mediciones. Debe construirse como un proyecto de investigación-acción y establecer desde su formulación inicial, sus propósitos y límites. En realidad, no es posible evaluarlo todo, en todo momento, ni en detalle; como en toda evaluación es necesario seleccionar la muestra de su contenido, precisar los métodos, procedimientos y técnicas a emplear, así como los criterios para su calificación.

Cada instituição de ensino possui sua forma peculiar de estabelecer relações e interação, sejam de natureza pessoal ou curricular. Embora se possam encontrar aspectos comuns em diversos espaços e tempos, isso não significa que atuarão da mesma forma. Pelo contrário, eles atuarão de maneira específica e singular, construindo sua própria identidade.

Assim compreendidas, as escolas médicas precisam fazer um esforço coletivo para entender o currículo como expressão do projeto pedagógico do curso, e o ensino-aprendizagem como um processo de construção do conhecimento e, em seu bojo, exigir da instituição educativa, do professor e do estudante diferentes capacidades e competências. Rosselot ${ }^{10}$ afirma que para a sustentação do

[...] proceso evaluador, para ponderar y retroalimentar el efecto de las innovaciones promovidas, y también, a la luz de la experiencia provista por la acreditación, se hace necesario, primero, convocar a una mayor participación directa de los alumnos, en la discusión de los programas para dar mayor validez a sus opiniones que la obtenida del análisis de las encuestas correspondientes. En segundo lugar, deberá implementarse el seguimiento de los egresados para tener mejor apreciación de las características obtenidas por quienes llevaron a cabo su aprendizaje en el entorno estudiantil de una institución que, como corresponde a sus expectativas, basa su tarea en las capacidades y competencia, disciplinaria y moral, de los que se formaron en ella. (p. 10-11)

Nesse contexto, a avaliação cumpre um papel fundamental e deve ser colocada a serviço da qualidade pedagógica do curso. Conforme Perim ${ }^{11}$,

a avaliação deve buscar a melhoria das condições de ensino-aprendizagem e ser capaz de identificar as potencialidades e fragilidades do curso. Deve ser um contínuo repensar sobre a formação, estimulando a mudança e a transformação, tendo como referência a excelência técnica e a relevância social do curso, bem como sua capacidade de dar respostas à sociedade. (p. 36)

Coerentemente com essa premissa, a avaliação na graduação médica assume importância especial, pois deve focalizar não só o conhecimento adquirido, mas também habilidades específicas e aspectos afetivos, como as atitudes frente a inúmeras situações ou aspectos da prática profissional.

Troncon $^{12}$ afirma que o reconhecimento progressivo dessa importância tem propiciado um grande desenvolvimento da área de avaliação de competências médicas no campo geral da educação médica. Essa evolução tem resultado numa diversidade de concei- 
tos e métodos aplicáveis a situações diversas na avaliação dos atores sociais do processo de formação médica, e também no aumento da complexidade e dificuldade inerentes à área.

Em seu estudo, Feuerwerker ${ }^{13}$ aponta alguns problemas comuns na avaliação da aprendizagem nas escolas médicas, entre eles: a utilização quase exclusiva da avaliação ao final da disciplina, cognitiva (com ênfase na memorização de conteúdos); a valorização de aspectos menos importantes do conteúdo das disciplinas; a desvalorização de mecanismos de avaliação diferentes da prova; a competitividade entre os estudantes (Lüdke e Salles apud Feuerwerker ${ }^{13}$, p. 73). A autora comprovou uma prática oposta no internato, onde, muitas vezes, não há mais provas e, sim, avaliações de desempenho, feitas de modo muito subjetivo, sem a definição de critérios conhecidos pelos avaliados.

Baffa $^{14}$ (p. 66) salienta que a prática avaliativa no internato médico deve ser democrática, dialógica, formativa e includente. Para tanto, sugere que os professores sejam agentes ativos na elaboração e discussão dos instrumentos de avaliação por eles utilizados e que participem de oficinas de capacitação e fóruns internos e externos de discussão sobre avaliação.

A autora sugere ainda que a instituição forneça informações detalhadas sobre as avaliações dos estudantes e realize: uma avaliação diagnóstica no início de cada estágio, visando identificar as deficiências dos estudantes a serem acompanhadas e minimizadas ao longo do período; uma avaliação somativa ao final de cada programa; e a avaliação formativa prioritariamente nas atividades práticas.

Perim ${ }^{11}$ amplia a discussão dessas dificuldades na avaliação do curso médico como um todo e não apenas no processo ensino-aprendizagem, pois

em função das dificuldades de organização e sistematização das informações, decorrentes da falta de integração das avaliações realizadas até então, e respaldados pelas diretrizes curriculares nacionais, onde estão previstos o acompanhamento e a avaliação do próprio curso, e não apenas do processo de ensino-aprendizagem [...] sentiu-se a necessidade de ampliação do modelo adotado, de forma a abranger a avaliação do curso como um todo. (p. 35)

A autora argumenta que, enquanto não se explicitam claramente os fins da avaliação, não se sabe ao certo a qual concepção de educação ela está servindo. Sendo assim, os levantamentos de dados só farão sentido se estiverem inseridos numa proposta de avaliação coerente com o modelo de educação que se preten- de. A autora alerta ainda para uma situação inversa, em que os instrumentos e resultados são utilizados veladamente para estabelecer o modelo ideal de educação. Nesse caso, os dados são meramente resultado de aferições ou medições, analisados quantitativamente, o que pode indicar muitos caminhos equivocados.

O modelo de avaliação proposto pela Universidade Estadual de Londrina (UEL) engloba o conjunto das dimensões que compõem o curso: projeto político-pedagógico; desenvolvimento da abordagem pedagógica e processo de ensino-aprendizagem; desenvolvimento das práticas nos cenários de ensino-aprendizagem; desenvolvimento do corpo docente; desenvolvimento do corpo discente; desenvolvimento do corpo técnico-administrativo; infraestrutura; desenvolvimento da gestão; e acompanhamento de ex-alunos (SIAMed ${ }^{15}$ ). Possibilita identificar as potencialidades e fragilidades do curso, por meio da opinião dos diversos segmentos envolvidos. Esse modelo engloba aspectos pedagógicos, estruturais e administrativos, visando estabelecer um plano de ação para o aprimoramento do curso. De acordo com o SIAMed ${ }^{15}$, a proposta se compõe de três fases: avaliação interna, avaliação externa e reavaliação, descritas a seguir.

- Avaliação interna - Consiste no levantamento e organização dos dados quantitativos e qualitativos do curso, com a participação efetiva das comunidades interna (estudantes, professores, gestores e funcionários) e externa local (profissionais de saúde, serviços de saúde, pacientes, lideranças comunitárias), o que resulta num conjunto estruturado de informações, possibilitando a construção coletiva de um retrato fiel e atualizado do curso.

- Avaliação externa - Representa um exame de fora para dentro da instituição. É complementar à autoavaliação e deve ser realizada a partir de sua consolidação junto à comunidade interna, ouvindo pares, egressos, lideranças, organizações e demais representações da sociedade organizada sobre o conjunto de informações que representam a totalidade do curso.

- Reavaliação - Retomada crítica do processo desenvolvido a partir dos resultados das avaliações interna e externa, com vistas a tomadas de decisão em busca do aperfeiçoamento do curso, mediante o desenvolvimento das seguintes etapas: discussão dos processos internos e externos no âmbito da comunidade acadêmica; reflexão sobre as potencialidades e as fragilidades do curso, identificadas a partir dos processos avaliativos; encaminhamento de propostas de mudança, tendo como pano de fundo o passado avaliado e o futuro projetado para o curso; reexame das práticas avaliativas e adequação do sistema de avaliação. 
Nessa perspectiva, a avaliação é um instrumento de compromisso de uma instituição consciente de sua responsabilidade social, uma vez que permite correções de rota durante o percurso, abrangendo todos os aspectos que compõem o curso e, mais do que isso, permite dar respostas à sociedade. Por meio de um processo avaliativo ético e responsável, a instituição poderá fazer uma reflexão crítica e participativa sobre suas ações e conhecer seu efetivo papel no engajamento com a comunidade e sua verdadeira contribuição para o desenvolvimento dela.

O exposto demonstra a importância da avaliação como força transformadora, em busca de uma instituição com excelência técnica e relevância social. Isto porque considera que a avaliação não se constitui apenas em seus produtos e resultados, mas, principalmente, na riqueza do processo avaliativo, no qual estudantes, professores, servidores, gestores e sociedade somam forças para superar as fragilidades da instituição identificadas em busca de seu aprimoramento.

Lopes e Silva ${ }^{16}$ também comungam dessa ideia, ao afirmarem que a avaliação institucional, na percepção da comunidade acadêmica,

vem se destacando não somente pelos resultados diretos produzidos em termos de análises e reflexões sobre o ensino, pesquisa, extensão e gestão, mas, também, pelo aprendizado gerado sobre o significado da Instituição e sobre a firmação de identidade que se transforma para atender mudanças sociais na comunidade regional e para além dela. [...] Uma avaliação, antes de tudo, deve representar um espaço de interlocução entre seus membros e da universidade com o seu entorno. Um espaço necessariamente democrático, de explicitação de valores e de confronto de concepções sobre a vida. Um espaço contínuo que mantenha a crítica como mecanismo orientador da prática cotidiana das instituições de ensino. (p. 52)

Assim, a avaliação preconizada deveria ser: útil, executável, ética e exata. Útil no sentido de possibilitar aos envolvidos numa ação educativa o julgamento do que vai bem e do que não vai bem com um dado processo ou resultado. Executável, isto é, sem perder o rigor, garantir a utilização de procedimentos compatíveis com a situação e as condições. Ética, no sentido de se comprometer com os direitos dos participantes e com a honradez dos resultados. Exata, por garantir o rigor na aplicação dos procedimentos e no julgamento dos resultados.
Os desafios enfrentados no momento atual exigem que a avaliação acrescente também o princípio da equidade e o comprometimento ou responsabilização dos agentes educativos. Avaliar com equidade significa analisar se a qualidade da educação oferecida atende igualmente a todos os setores sociais. E a responsabilidade para garantir a equidade é de toda a sociedade, sobretudo dos governos, e exige o compromisso expresso e definitivo dos agentes do processo educacional. Assim, refletir sobre avaliação recoloca diante dos investigadores a questão do poder na educação, em várias instâncias com as instituições escolares: dos órgãos governamentais; da sociedade e da família; dos dirigentes educacionais com os docentes e pessoal de apoio técnico-administrativo; dos docentes com os discentes.

No âmbito educacional, existe uma tendência em focar a avaliação da aprendizagem num sentido limitado, como se ela pudesse dar conta de toda a complexidade que abarca a avaliação da educação. Daí a importância de compreender o ato de avaliar a educação como um fenômeno que ultrapassa a avaliação da aprendizagem do estudante, uma vez que deve configurar uma experiência negociada e que reflita os princípios que fundamentam uma instituição formativa.

Na opinião de Feuerwerker ${ }^{13}$, é indispensável entender que a avaliação da aprendizagem visa coletar informações sobre o desempenho dos alunos para aperfeiçoar o processo de ensino-aprendizagem; identificar os interesses de cada estudante para melhor orientá-los; julgar quais experiências educacionais são mais úteis para diversos grupos de estudantes; verificar se os programas educacionais estão provocando reais mudanças; proporcionar elementos para que o professor possa planejar o nível e o tipo de atividade educacional adequados:

A avaliação pode ser feita antes (diagnóstica), durante (formativa) e ao final (somativa) de um determinado momento de ensino-aprendizagem. De acordo com os objetivos educacionais, pode estar voltada a avaliar conhecimentos (cognitiva), atitudes (afetiva) ou habilidades (psicomotora) e pode ser realizada através de metodologias quantitativas ou qualitativas. (p.73-4)

Outro aspecto a considerar, do mesmo nível de importância, é o dos padrões de referência avaliativa. Há padrões absolutos, que se apoiam nos objetivos educacionais e geralmente são usados para as avaliações somativas. E também padrões relativos, baseados em referência por critério ou em referência por norma. Os testes referentes a critério são planejados para obter informações sobre conhecimentos e capacidades específicos do estudan- 
te, ou seja, para saber o que o estudante pode ou não fazer. São muito úteis para avaliação formativa ${ }^{13}$.

Independentemente da modalidade, é de fundamental importância definir objetivos de aprendizagem para aquele momento do curso: comparar esses objetivos de aprendizagem específicos com os gerais, para que sejam coerentes com a proposta do curso; avaliar o processo, o produto ou o resultado da atividade. Há uma diversidade de instrumentos avaliativos - quantitativos e qualitativos -, uns mais adequados do que outros, dependendo dos objetivos da avaliação.

A avaliação formativa é um mecanismo muito útil, tanto aos professores quanto aos estudantes, para que possam identificar problemas e corrigir rumos. Esse momento permite avaliar todas as dimensões da aprendizagem e garantir que o conteúdo da avaliação seja coerente com os objetivos educacionais delineados. Na avaliação cognitiva, é importante explorar outros aspectos, não apenas os de retenção da informação (de memorização), e avançar para aplicação e análise.

Na opinião de Álvarez Méndez ${ }^{17}$, avaliamos para

conhecer quando corrigimos construtiva e solidariamente com quem aprende, não para confirmar ignorâncias, desqualificar esquecimentos, penalizar aprendizagens não adquiridas. Quando os professores agem como corretores que explicam e comunicam razoavelmente, são fonte de aprendizagem mediante informação compreensível e argumentada que devem fornecer nessa tarefa. (p. 83)

É importante salientar que a diferença principal da avaliação formativa em relação à medida é a intencionalidade. Enquanto a avaliação de medida aspira verificar a aprendizagem, a avaliação formativa busca conhecer a fronteira dessa aprendizagem para a tomada de decisões a fim de otimizá-la.

No processo de avaliação alguns aspectos são fundamentais, como: os critérios e as condições do processo avaliativo, que devem ser conhecidos antecipadamente por todos os sujeitos envolvidos; a diversificação de fontes de informação, para evitar entraves técnicos e pessoais. É importante que essas fontes sejam o próprio estudante (autoavaliação), os colegas (avaliação interpares), os docentes (avaliação do tutor/instrutor) e a própria comunidade.

Dessa forma, a avaliação implica obter informações, por meio da aplicação de métodos específicos, que podem subsidiar a tomada de decisões que interessam tanto ao processo do aprendizado quanto ao educando. Nesse contexto, a avaliação pode ser entendida como um processo de comparação entre os dados do desempenho do estudante e os objetivos instrucionais previamente estabelecidos (Tyler apud Troncon ${ }^{12}$, p. 430).
Essas definições, ligeiramente diferentes, trazem consigo alguns componentes básicos indissociáveis do conceito genérico de avaliação. Entre eles, deve-se ressaltar o juízo de valor aplicado sobre os resultados do emprego de métodos apropriados, tendo em vista padrões preestabelecidos. Muito frequentemente, o juízo é estabelecido com base na apreciação de medidas feitas com escalas apropriadas, em comparação a critérios quantitativos previamente definidos (Pophan apud Troncon ${ }^{12}$, p. 430). Em qualquer caso, a valoração é feita com vistas a finalidades específicas, que justificam e norteiam a avaliação.

Uma vez que as estratégias de avaliação discente e docente constituem importantes variáveis a serem consideradas na avaliação da educação médica, merecem destaque alguns aspectos básicos sobre a avaliação desses dois atores no processo de ensino-aprendizagem.

\section{AVALIAÇÃO DO ESTUDANTE}

$\mathrm{Na}$ avaliação do estudante de Medicina, pode-se adotar o conceito genérico de que esta é um processo de coleta de informações, realizado por meio de atividades sistemáticas e formais, que permite saber o que o estudante conhece, sabe fazer e, efetivamente, faz de modo adequado, de maneira que se possa interferir no processo educacional, corrigindo distorções e reforçando aspectos positivos. Evidentemente, essa interferência deve repercutir no sujeito central do processo educacional, o estudante de Medicina.

Em decorrência desse conceito, a avaliação pressupõe o estabelecimento prévio, com a maior precisão possível, do conjunto de habilidades a serem adquiridas, cujo domínio, demonstrado na avaliação pertinente, permitirá atestar o alcance dos objetivos instrucionais.

Assim, a avaliação abrangente do estudante de Medicina deverá cobrir todas estas habilidades, competências e características pessoais em seus diferentes domínios. Entretanto, isto só ocorrerá mediante a utilização de uma diversidade de procedimentos e de instrumentos voltados para aspectos específicos.

Para Troncon $^{12}$ (p. 432), o interesse em avaliar não se restringe ao que o estudante aprendeu e também engloba se ele "aprendeu a aprender". Este aspecto é da maior atualidade, em face da rapidez com que os conceitos mudam na medicina e da espantosa velocidade com que o conhecimento médico se acumula. Assim, o estudante deve ter uma atitude de aprendizado contínuo, como também deve dominar as habilidades necessárias à busca de informações nas fontes adequadas, usando os recursos convenientes.

O autor salienta que os principais recursos para avaliação de habilidades cognitivas são provas escritas, com questões objetivas ou dissertativas, e outras formas alternativas, como: estudo 
de casos, relatórios, provas orais, elaboração de projetos, revisões e críticas, e problemas de manejo de pacientes. Na avaliação de competências e habilidades clínicas, os recursos básicos são as observações assistemáticas, observações sistemáticas, exames - de desempenho, exame objetivo estruturado por estações e exame de desempenho clínico. Entretanto, é importante distinguir a avaliação de competências e a avaliação de desempenho.

Para Perrenoud ${ }^{18}$, a construção de competências é inseparável da formação de esquemas de mobilização dos conhecimentos com discernimento, em tempo real, a serviço de uma ação eficaz. Ou seja, o desenvolvimento de competências envolve o sujeito como um todo, compreendendo a capacidade de dar respostas efetivas e eficazes de acordo com a situação, o que gera avaliação multifacetada, na tentativa de apreender seus diversos componentes. Na opinião de Depresbiteris ${ }^{19}$ (p. 31-2), a avaliação de competências, de forma simplificada, inclui: análise do perfil profissional, definição de critérios de qualidade e evidências para a avaliação, indicadores e estabelecimento de técnicas e instrumentos de avaliação.

É importante lembrar que os indicadores são evidências utilizadas para julgar se uma pessoa atende ou não aos critérios. Ao se assumir que um indicador é um construtor teórico, surge a necessidade de identificá-lo antes da análise de dada realidade. Neste caso, cada critério define o que se julga poder esperar, legitimamente, do objeto avaliado. Portanto, é por meio dos critérios que se pode interpretar o objeto em estudo. Para Hadji ${ }^{20}$, é a coerência entre critérios e indicadores que possibilita equilibrar subjetividade e objetividade.

Entre os procedimentos a utilizar na avaliação de competências, destacam-se: a resolução de problemas em situações simuladas a partir da realidade; a análise de casos (escritos, em vídeo); a elaboração de portfolio (compilação de trabalhos realizados por uma pessoa, evidências de sua história profissional, casos interessantes, relatórios, projetos, ensaios autorreflexivos) ${ }^{19}$ (p. 34-5).

Em suma, a avaliação formativa se desenvolve ao longo do processo ensino-aprendizagem e permite ao estudante compreender suas forças e fragilidades nas diversas áreas. Facilita ao estudante se reposicionar ao longo do processo, além de permitir rever estratégias de ensino. É importante observar que a escolha e a aplicação de um procedimento para obter resultados definidos são um meio para atingir determinadas metas que resultam no aprimoramento da educação do estudante, e não num fim em si mesmo. Finalmente, a autora assinala que a avaliação deve servir:
- como monitoramento do currículo e controle da eficiência do ensino e do aprendizado;

- como provisão de reforço, aos estudantes e aos professores, como agentes principais do processo do ensino e do aprendizado;

- de estímulo e orientação ao aprendizado individual dos estudantes;

- de meio de obtenção de consenso sobre o que é importante ensinar e aprender;

- como garantia de obtenção de nível adequado de competência e de segurança quanto à obediência a padrões mínimos de qualidade do desempenho profissional dos estudantes que se graduam; o cumprimento desta função pela escola médica é de importância crucial, principalmente nos países em que os órgãos de controle do exercício profissional se eximem deste dever ${ }^{12}$ (p. 438).

\section{AVALIAÇÃO DO DOCENTE}

De acordo com Dantas ${ }^{21}$ :

a mudança de ênfase de uma aprendizagem principalmente passiva para uma outra que seja mais ativa exige a preparação dos docentes para a condução competente de grupos pequenos de alunos. A função de facilitador de grupos (ou de tutor, na tradição anglo-saxônica) exige o domínio de várias habilidades interpessoais (em particular a de saber ouvir) que têm sido quase totalmente negligenciadas na formação dos nossos docentes médicos. [...] A abordagem de problemas sob uma perspectiva holística ou integrativa - percebendo causas e mecanismos muito além do simples raciocínio fisiopatológico exige do profissional um esforço de atualização com a realidade que o cerca para ajudar a correta contextualização do problema em discussão. (p. 2 aprox.)

Na opinião do autor, o tutor idealizado deveria ser um especialista tanto no conteúdo estudado pelos alunos quanto nas funções tutoriais de facilitação da aprendizagem. Se não o for, é fundamental que domine bem as habilidades de facilitação da aprendizagem em grupo. São inaceitáveis, em grupos tutoriais, professores especialistas no tema, porém fracos tutores, com baixo domínio das habilidades tutoriais.

A transformação do papel do tutor o torna mais importante do que o papel do facilitador ou do transmissor, já que o tutor ne- 
cessita trabalhar num contexto criativo, aberto, dinâmico, complexo. Isso modifica o cenário de ação educativa: em vez da adoção de programas lineares, fechados, estabelecidos a priori, passa-se a trabalhar com estratégias de ação que podem ser alteradas em função das informações, dos acontecimentos, dos imprevistos que sobrevenham no curso dessa ação ${ }^{22}$ (p. 284-5). Isto implica trabalhar com incertezas, com complexidades.

Nesse contexto, pode-se entender que a avaliação deve ser uma âncora norteada principalmente pela percepção dos docentes e dos estudantes para respaldar as mudanças necessárias à construção de uma autoavaliação resultante de discussão aberta, ampla e democrática, que reflita a realidade dinâmica de um ensino de qualidade ${ }^{21}$.

Portanto, a autoavaliação de desempenho docente (tutor/instrutor) do curso médico, na abordagem crítico-reflexiva, deve "respeitar a nossa cultura e o estágio da nossa caminhada, sem descuidar de melhorar alternativas com as quais nossos docentes e alunos já estão acostumados"21 (p.3 aprox.).

Isso justifica assumir a autoavaliação como um mecanismo de autoaperfeiçoamento que considera o docente como sujeito histórico-social e criador, capaz de aprender, de desaprender e de reaprender. Para Mourão ${ }^{23}$,

[...] a autoavaliação é um processo através do qual se desenvolve uma análise entre as pessoas que intervêm em seu meio de trabalho, com o propósito de conseguir que o professor reflita sobre suas forças e insuficiências, obtendo melhoramento em seu desempenho profissional e humano. (p. 30)

Esta definição evidencia que a autoavaliação é um processo de crescimento do professor em sua função educativa, assim como já dito do estudante. Sem esquecer a complexidade da tarefa do educador, que implica participar da formação do caráter, da personalidade, da consciência crítica do educando, tendo como mediação conhecimentos historicamente elaborados e relevantes.

Portanto, o autoaperfeiçoamento constitui a possibilidade que tem o docente de reconhecer e modificar sua forma de atuação em seu fazer pedagógico. Isto porque o processo está mediado por uma reflexão que ocorre tanto no plano interno (individual) quanto no externo (entre estudantes, colegas e grupos).

\section{CONCLUSÃO}

É preciso definir claramente as funções e objetivos da avaliação do curso médico, com ampla divulgação, para que todos os envolvidos no processo possam refletir sobre suas ações, a fim de corrigir as distorções percebidas por estes na execução do curso. Isto requer a formulação, a negociação e a explicitação prévia dos critérios e indicadores que serão utilizados no processo avaliativo.

A avaliação deve estar presente em todos os cenários de ensino-aprendizagem e seus critérios de progressão, recuperação e reprovação sistematizados. Atualmente, a maioria dos cursos médicos trabalha com o referencial de competência profissional. É importante salientar que a avaliação de competência pode ser deduzida por meio da observação dos desempenhos em cada atividade proposta, organizada em grau crescente de complexidade nas áreas de atuação em todos os ambientes do processo educativo.

Também é preciso conhecer as características dos processos não só para identificar as causas e efeitos dos resultados, mas para adotar medidas que possam contribuir de fato para o aperfeiçoamento do ensino e, por conseguinte, a efetivação da aprendizagem.

A avaliação deve ser colocada a serviço das aprendizagens, exigindo que os educadores redefinam tanto o seu conceito quanto a sua prática, para que possam promover o movimento contínuo entre os territórios do saber e do não saber de seus estudantes.

É necessário, ainda, que haja coerência num sistema de avaliação que considere a relação mútua existente entre os aspectos qualitativos e quantitativos desse processo, a natureza da relação pedagógica e os objetivos que se propõe alcançar, visto que a complexidade do processo de ensino evolui de maneira dinâmica. Portanto, a avaliação na escola médica deve assumir a dificuldade que a consideração simultânea de todos estes componentes implica ao longo de seu desenvolvimento.

Buscou-se neste estudo desenvolver um trabalho crítico, considerando não ser possível pensar num processo de avaliação descolado e descontextualizado de condições estruturais mais amplas que apreendam as contradições da realidade. A reflexão aqui desenvolvida sobre avaliação na escola médica permanece aberta, inacabada e desafiadora, com a força educativa que tem o próprio processo avaliativo.

\section{REFERÊNCIAS}

1. Instituto Nacional de Estudos e Pesquisas Educacionais Anísio Teixeira. Sistema Nacional de Avaliação da Educação Superior: da concepção à regulamentação. $2^{\underline{a}}$ ed., ampl. Brasília: INEP; 2004.

2. Farias LC. Implicações conceituais para uma prática avaliativa. Palestra proferida aos membros da Comissão Central de 
Graduação da UNICAMP em 22/02/2001. [documento na internet]. [acesso em 20 abr. 2008]. Disponível em: www.prg.rei.unicamp.br/implicacoes_conceituais_pratica_aval_luiz_carlos.htm

3. Dias CL, Horiguela MLM, Marchelli PS. Políticas para avaliação da qualidade do Ensino Superior no Brasil: um balanço crítico. Educ Pesqui. 2006;32:435-64.

4. Rothen JC, Schulz A. Sinaes: do documento original à legislação. Rev. Diálogo Educ. 2007;7(21):163-80.

5. Faria G. Sinaes: a proposta de avaliação da Educação Superior. Beira do Rio 2003 out. 30; p.8. Maria José Oliveira e Silva Jaskson Costa: entrevistada do mês do Jornal Beira Rio

6. Ristoff D, Giolo J. O Sinaes como Sistema. RBPG. 2006;3(6):193-213.

7. Dias Sobrinho J, Ristoff DI (Orgs.). Avaliação e compromisso público: a educação superior em debate. Florianópolis: Insular; 2003.

8. BRASIL. Ministério da Educação. Sistema Nacional de Avaliação da Educação Superior SINAES: bases para uma nova proposta de avaliação da educação superior. [documento na internet]. Brasília: MEC; 2003. [acesso em 20 abr. 2008]. Disponível em: http:/ /www.mec.gov.br/acs/pdf/sinaes.

9. Perez Sanchez AM, Leticia Maria BA. La evaluación como actividad orientada a la transformación de los procesos formativos. Educ Med Super. [periódico na internet]. 2004;18(4). [acesso em 10 mar. 2008]. Disponível em: http://scielo.sld.cu/scielo.php?script=sci_.

10. Rosselot JE. Acreditación de Escuelas de Medicina: Trabajando para la calidad y la confiabilidad pública. Rev. Méd. Chil. 2001;129(8):935-943.

11. Perim GL. Avaliação do ensino médico e da educação superior: uma experiência local frente à proposta do Sistema Nacional de Avaliação. Olho Mágico. 2004;11(1/2):31-39.

12. Troncon LA. Avaliação do estudante de medicina. Medicina (Ribeirão Preto). 1996;29:429-39.

13. Feuerwerker LCM. Mudanças na educação médica: os casos de Londrina e Marília. São Paulo; 2002. Doutorado [Tese]- Universidade de São Paulo.

14. Baffa AM. Internato médico: desafios da avaliação da aprendizagem em serviço. Campinas; 2008. Mestrado [Dissertação]-Pontifícia Universidade Católica de Campinas.

15. Universidade Estadual de Londrina. Colegiado do Curso de Medicina. Sistema Integrado de Avaliação do Curso de Medicina. Avaliação Interna e Externa do Curso de Medicina da UEL:
2003-2005: resultados e encaminhamentos. [documento na internet]. Informe Avaliativo. 2005;3(24) Ed. Especial. [acesso em 12 abr. 2008]. Disponível em: http://www.ccs.uel.br/medicina/siamed/informe24.pdf

16. Lopes FD, Silva, IB. UNIJUI: uma experiência de avaliação institucional participativa. Avaliação: Rev Rede Avaliação Institucional Educ Superior. 1998;3(2).

17. Álvarez Méndez JM. Avaliar para conhecer, examinar para excluir. Porto Alegre: Artmed; 2002.

18. Perrenoud P. Construir as competências desde a escola. Porto Alegre: Artes Médicas; 1999.

19. Depresbiteris L. Avaliando competências na escola de alguns ou na escola de todos? Boletim Técnico do SENAC (RJ). 2001;27(3):36-47.

20. Hadji C. A avaliação desmistificada. Porto Alegre: Artmed; 2001.

21. Dantas F. Aprendizagem Baseada em Problemas: mudando um padrão de aprendizagem em medicina. [peiodico na internete] Med On line. 1998 [acesso em 12 abr. 2008] 1(1). Disponível em: http://www.medonline.com.br/med_ed/med1/dantas.htm ;

22. Morin E. Epistemologia da complexidade. Novos paradigmas, cultura e subjetividade. Porto Alegre: Artes Médicas; 1996. p. 274-289.

23. Mourão, MGM. Auto-avaliação como processo para o auto-aperfeiçoamento do docente. Rev Educ Significante. 2004;1(1):27-38.

\section{CONTRIBUIÇÃO DOS AUTORES}

Os autores Antônio Prates Caldeira e José J. B.Vasconcelos Raposo participaram da elaboração deste trabalho, desde a revisão de literatura, produção e revisão do mesmo. O primeiro é orientador e o segundo é co-orientador na minha pesquisa de Doutorado.

\section{CONFLITO DE INTERESSES}

Declarou não haver.

\section{ENDEREÇO PARA CORRESPONDÊNCIA}

Maria das Graças Mota Mourão

Rua São Geraldo, 159

Todo os Santos - Montes Claros

CEP.: 39400-140 MG

E-mail:mg_mourao@hotmail.com 